\title{
Breaking the local symmetry of $\mathrm{LiCoO}_{2}$ via atomic doping for efficient oxygen evolution
}

Zhirong Zhang, ${ }^{\dagger, l l}$ Chunxiao Liu, ${ }^{\dagger, l}$ Chen Feng, ${ }^{\dagger, l}$ Pengfei Gao, ${ }^{\dagger}$ Yulin Liu, ${ }^{\dagger}$ Fangning Ren, ${ }^{\dagger}$ Yifeng Zhu, ${ }^{\dagger}$ Cong Cao,${ }^{\dagger}$ Wensheng Yan, ${ }^{\dagger}$ Rui Si,,$\$$ Shiming Zhou ${ }^{*}, \dagger$, Jie Zeng ${ }^{*}, \dagger$

HHefei National Laboratory for Physical Sciences at the Microscale, Key Laboratory of Strongly-Coupled Quantum Matter Physics of Chinese Academy of Sciences, National Synchrotron Radiation Laboratory, Key Laboratory of Surface and Interface Chemistry and Energy Catalysis of Anhui Higher Education Institutes, Department of Chemical Physics, University of Science and Technology of China, Hefei, Anhui 230026, P. R. China

\$Shanghai Synchrotron Radiation Facility, Shanghai Institute of Applied Physics, Chinese Academy of Sciences, Shanghai 201204, P. R. China

*To whom correspondence should be addressed.

E-mail: zhousm@ustc.edu.cn (S. Z.)

E-mail: zengj@ustc.edu.cn (J. Z.)

'These authors contributed equally to this work. 


\section{Experimental Details}

Chemicals. $\mathrm{LiNO}_{3}, \mathrm{Co}\left(\mathrm{NO}_{3}\right)_{2} \cdot 6 \mathrm{H}_{2} \mathrm{O}, \mathrm{La}\left(\mathrm{NO}_{3}\right)_{3} \cdot 6 \mathrm{H}_{2} \mathrm{O}, \mathrm{Nd}\left(\mathrm{NO}_{3}\right)_{3} \cdot 6 \mathrm{H}_{2} \mathrm{O}, \mathrm{Gd}\left(\mathrm{NO}_{3}\right)_{3} \cdot 6 \mathrm{H}_{2} \mathrm{O}$, citric acid monohydrate, and isopropyl alcohol were purchased from Shanghai Chemical Reagent Company. All chemicals were of analytical grade and used without further purification. Active carbon and Nafion were purchased from Sigma Aldrich. All aqueous solutions were prepared using deionized water with a resistivity of $18.2 \mathrm{M} \Omega \mathrm{cm}^{-1}$.

Synthesis of pristine $\mathrm{LiCoO}_{2}$. Pristine $\mathrm{LiCoO}_{2}$ was prepared via a sol-gel method. Stoichiometric amounts of $\mathrm{LiNO}_{3}$ and $\mathrm{Co}\left(\mathrm{NO}_{3}\right)_{2} \cdot 6 \mathrm{H}_{2} \mathrm{O}$ were mixed and dissolved in deionized water. Citric acid monohydrate was then added as a complexing agent with a molar ratio of 1:1 for total metallic ions: citric acid. Subsequently, the as-obtained transparent solution was heated to $150{ }^{\circ} \mathrm{C}$ on a hot plate under constant stirring to form a gel. Finally, the gel of $\mathrm{LiCoO}_{2}$ was calcined in air at $700{ }^{\circ} \mathrm{C}$ for $5 \mathrm{~h}$ to obtain samples with good crystallinity.

Synthesis of $\mathrm{La} / \mathrm{LiCoO}_{2}$ with different ratios of $\mathrm{La}$. The preparation of $\mathrm{x} \% \mathrm{La} / \mathrm{LiCoO}_{2}(\mathrm{x}=0.5$, 1, and 2) used the same method as the preparation of pristine $\mathrm{LiCoO}_{2}$, except for dissolving stoichiometric amounts of $\mathrm{LiNO}_{3}, \mathrm{Co}\left(\mathrm{NO}_{3}\right)_{2} \cdot 6 \mathrm{H}_{2} \mathrm{O}$, and $\mathrm{La}\left(\mathrm{NO}_{3}\right)_{3} \cdot 6 \mathrm{H}_{2} \mathrm{O}$ in deionized water.

Synthesis of $1 \% \mathrm{Nd} / \mathrm{LiCoO}_{2}$ and $1 \% \mathbf{G d} / \mathrm{LiCoO}_{2} .1 \% \mathrm{Nd} / \mathrm{LiCoO}_{2}$ and $1 \% \mathrm{Gd} / \mathrm{LiCoO}_{2}$ were synthesized following the same procedures as synthesizing $1 \% \mathrm{La} / \mathrm{LiCoO}_{2}$, except for replacing $\mathrm{La}\left(\mathrm{NO}_{3}\right)_{3} \cdot 6 \mathrm{H}_{2} \mathrm{O}$ with $\mathrm{Nd}\left(\mathrm{NO}_{3}\right)_{3} \cdot 6 \mathrm{H}_{2} \mathrm{O}$ or $\mathrm{Gd}\left(\mathrm{NO}_{3}\right)_{3} \cdot 6 \mathrm{H}_{2} \mathrm{O}$.

Electrochemical measurements. Electrochemical tests were conducted on a CHI660E electrochemical workstation (Shanghai $\mathrm{CH}$ Instruments) with a three-electrode system in oxygen-saturated $0.1 \mathrm{M} \mathrm{KOH}$ electrolyte. A carbon rod and an $\mathrm{Ag} / \mathrm{AgCl}$ electrode was used as the counter electrode and reference electrode, respectively. The measured potentials against $\mathrm{Ag} / \mathrm{AgCl}$ electrode were all converted to reversible hydrogen electrode (RHE) scale according to $E(\mathrm{vs} \mathrm{RHE})=E(\mathrm{vs} \mathrm{Ag} / \mathrm{AgCl})+0.965 \mathrm{~V}$. Then, $E(\mathrm{vs} \mathrm{RHE})$ was $i R$-corrected to compensate the solution resistance $R$ by $E_{i R \text {-corrected }}=E(\mathrm{vs}$ RHE) $-i R$, where $i$ is the current, and $R$ is $36 \Omega$ in 0.1 $\mathrm{M} \mathrm{KOH}$ electrolyte. A glassy carbon electrode was used as the working electrode. For the preparation of the working electrode, $3 \mathrm{mg}$ of catalysts and $3 \mathrm{mg}$ of active carbon were dispersed 
in a mixture containing $1 \mathrm{~mL}$ of deionized water, $0.25 \mathrm{~mL}$ of isopropyl alcohol, and $50 \mu \mathrm{L}$ of Nafion (5\%). The mixture was then sonicated for $1 \mathrm{~h}$ to form a homogeneous catalyst ink. Next, $5 \mu \mathrm{l}$ of this ink was drop-casted onto a 5-mm-diameter glassy carbon electrode and dried naturally, yielding a catalyst loading of $0.06 \mathrm{mg} \mathrm{cm}^{-2}$. The polarization curves were measured using a linear sweep method and recorded from 1.10 to $1.80 \mathrm{~V}$ at a sweep rate of $5 \mathrm{mV} \mathrm{s}^{-1}$. Durability test was performed at room temperature in galvanostatic mode at a current density of $10 \mathrm{~mA} \mathrm{~cm}{ }^{-2}$. Specific activities were obtained by normalizing the current densities against both real surface areas measured from BET and electrochemically active surface areas (ECSA). ECSA was acquired according to the equation: ECSA $=R_{\mathrm{f}} S$, where $R_{\mathrm{f}}$ is the roughness factor and $S$ is the geometric area of glassy carbon electrode. In this work, $S=0.196 \mathrm{~cm}^{-2}$. $R_{\mathrm{f}}$ was determined by $R_{\mathrm{f}}=C_{\mathrm{dl}} / 60 \mu \mathrm{F} \mathrm{cm} \mathrm{cm}^{-2}$ based on the double-layer capacitance $\left(C_{\mathrm{dl}}\right)$ of a smooth oxide surface $\left(60 \mu \mathrm{F} \mathrm{cm}{ }^{-2}\right) . C_{\mathrm{dl}}$ was estimated by plotting the $\Delta j\left(j_{a}-j_{c}\right)$ at $0.75 \mathrm{~V}$ vs RHE against a scan rate of $20,40,60,80$, and $100 \mathrm{mV} \mathrm{s}^{-1}$, respectively. $\Delta j$ was acquired by cyclic voltammetry (CV) measurement under the potential windows of $0.7 \sim 0.8 \mathrm{~V}$ vs RHE at a sweep rate of $1 \mathrm{mV}$ $\mathrm{s}^{-1} \cdot j_{a}$ and $j_{c}$ responds to the highest and the lowest current density value at $0.75 \mathrm{~V}$, respectively. Tafel slopes were calculated by fitting the linear portion of the polarization curves to the Tafel equation: $\eta=b \log j+c$, where $\eta$ is the overpotential, $b$ is the Tafel slope, $j$ is the current density, and $c$ is the intercept. Electrochemical impedance spectroscopy (EIS) was conducted with alternating-current voltage with $5 \mathrm{mV}$ amplitude at the potential of $1.53 \mathrm{~V}$ vs RHE within the frequency range from $100 \mathrm{KHz}$ to $100 \mathrm{mHz}$.

Computational details. We performed DFT $+U$ calculations within the Vienna ab initio simulation package (VASP) using the projector augmented wave (PAW) potentials. ${ }^{[\mathrm{S} 1-3]}$ We adopted the Perdew-Burke-Ernzerhof (PBE) functional together with the Hubbard-U method to calculate the $d$-electron of $\mathrm{Co}$ atoms and $f$-electron of La atoms. ${ }^{[\mathrm{S} 4-5]}$ The effective onsite Coulomb terms $U_{\text {eff }}=\mathrm{U}-\mathrm{J}$ for $\mathrm{Co}$ and $\mathrm{La}$ atoms were chosen to be 4.9 and $7.5 \mathrm{eV}$, respectively. ${ }^{[\mathrm{S} 6]}$

The bulk optimization calculations were performed in a $3 \times 3 \times 1$ supercell, containing 27 $\mathrm{LiCoO}_{2}$ formula units (27 $\mathrm{Li}$ atoms, $27 \mathrm{Co}$ atoms, and $54 \mathrm{O}$ atoms). The doped $\mathrm{LiCoO}_{2}$ system was modeled by substituting one out of $27 \mathrm{Co}$ ions with a La ion. The Monkhorst-Pack scheme with $3 \times 3 \times 2$ k-point mesh was used. ${ }^{[\mathrm{S} 7]}$ The cutoff energy for the plane wave expansion was 
chosen to be $550 \mathrm{eV}$. The total energy was converged within $1 \times 10^{-5} \mathrm{eV}$. The lattice parameters and ionic positions were both relaxed. The final forces on all ions were less than $0.01 \mathrm{eV} / \AA$.

Characterization. The phase purity and crystal structure of the samples were determined by $\mathrm{X}$-ray diffraction at room temperature on a Rigaku TTR-III diffractometer using $\mathrm{Cu} \mathrm{K} \alpha$ radiation $(\lambda=1.5418 \AA)$. TEM images were taken on a Hitachi H-7650 transmission electron microscope at an acceleration voltage of $100 \mathrm{kV}$. The HRTEM and EELS were collected on a JEOL ARM-200F field-emission transmission electron microscope operating at an acceleration voltage of $200 \mathrm{kV}$. The EELS spectra were recorded in single-atom La areas. XPS were carried out on an ESCALAB $250 \mathrm{X}$-ray photoelectron spectrometer with $\mathrm{Al} \mathrm{K} \alpha$ as the excitation source. The nitrogen adsorption-desorption isotherms were conducted on a Micromeritics ASAP 2000 system at $77 \mathrm{~K}$. The XAS spectra at Co $L$-edge were performed at Hefei Synchrotron Radiation Facility. The XANES spectra at La $K$-edge $\left(E_{0}=38925 \mathrm{eV}\right)$ were performed at BL14W1 beamline at Shanghai Synchrotron Radiation Facility. The XANES data on $\mathrm{La} / \mathrm{LiCoO}_{2}$ samples with different ratios of La were recorded under fluorescence mode with a Lytle ion chamber. The conductivities of the prepared catalysts as a function of temperature were measured with a four-probe configuration on a Quantum Design Physical Property Measurement System (PPMS) cooling process with a rate of $-4 \mathrm{~K} / \mathrm{min}$.

Data availability. The data that support the findings of this study are available from the corresponding author on request. 

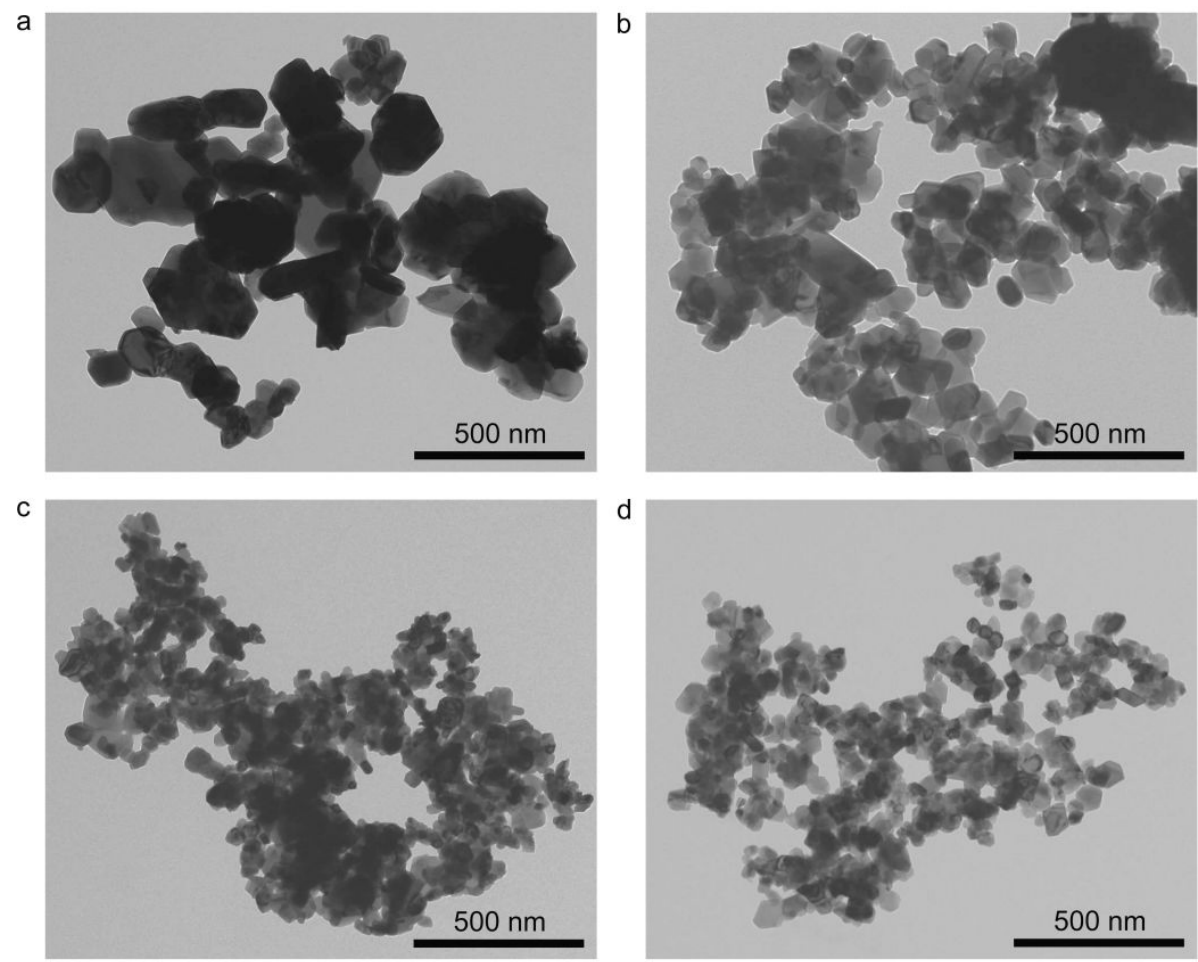

Figure S1. TEM images of (a) pristine $\mathrm{LiCoO}_{2}$, (b) $0.5 \% \mathrm{La} / \mathrm{LiCoO}_{2}$, (c) $1 \% \mathrm{La} / \mathrm{LiCoO}_{2}$, and (d) $2 \% \mathrm{La} / \mathrm{LiCoO}_{2}$, respectively. 


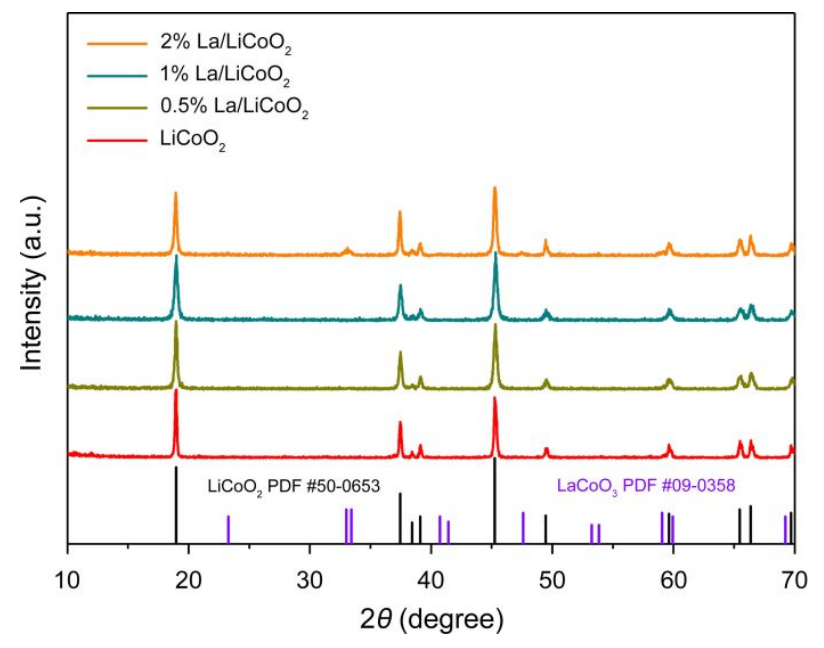

Figure S2. XRD patterns of pristine $\mathrm{LiCoO}_{2}$ and $\mathrm{x} \% \mathrm{La} / \mathrm{LiCoO}_{2}(\mathrm{x}=0.5,1$, and 2). 
Table S1. Comparison of OER activities for $\mathrm{LiCoO}_{2}$-based electrocatalysts.

\begin{tabular}{|c|c|c|c|}
\hline Catalysts & Electrolyte & $\eta @ j=10 \mathrm{~mA} \mathrm{~cm}-2(\mathrm{~V})$ & Ref. \\
\hline $1 \% \mathrm{La} / \mathrm{LiCoO}_{2}$ & $0.1 \mathrm{M} \mathrm{KOH}$ & 0.33 & \multirow{2}{*}{ This work } \\
\hline pristine $\mathrm{LiCoO}_{2}$ & 0.1 М КОН & 0.44 & \\
\hline $\mathrm{LiCoO}_{2}$ & $0.1 \mathrm{M} \mathrm{KOH}$ & $\sim 0.41$ & \multirow{2}{*}{ S8 } \\
\hline $\mathrm{Li}_{0.5} \mathrm{CoO}_{2}$ & $0.1 \mathrm{M} \mathrm{KOH}$ & $\sim 0.39$ & \\
\hline $\mathrm{LiCo}_{0.33} \mathrm{Ni}_{0.33} \mathrm{Fe}_{0.33} \mathrm{O}_{2}$ & $0.1 \mathrm{M} \mathrm{KOH}$ & $>0.42$ & \multirow[b]{2}{*}{ S9 } \\
\hline $\begin{array}{c}\text { Delithiated } \\
\mathrm{LiCo}_{0.5} \mathrm{Fe}_{0.5} \mathrm{O}_{2}\end{array}$ & $0.1 \mathrm{M} \mathrm{KOH}$ & $\sim 0.36$ & \\
\hline $\begin{array}{c}\text { Delithiated } \mathrm{Li}_{0.5} \mathrm{CoO}_{2} \\
\text { nanoparticles }\end{array}$ & $0.1 \mathrm{M} \mathrm{KOH}$ & 0.39 & $\mathrm{~S} 10$ \\
\hline $\mathrm{LiCo}_{0.8} \mathrm{Fe}_{0.2} \mathrm{O}_{2}$ & $0.1 \mathrm{M} \mathrm{KOH}$ & 0.34 & $\mathrm{~S} 11$ \\
\hline Li-Ni-Mn-Co-OH & $0.1 \mathrm{M} \mathrm{NaOH}$ & 0.35 & $\mathrm{~S} 12$ \\
\hline $\mathrm{LiCoO}_{2}$ nanosheets & $0.1 \mathrm{M} \mathrm{KOH}$ & 0.41 & $\mathrm{~S} 13$ \\
\hline
\end{tabular}



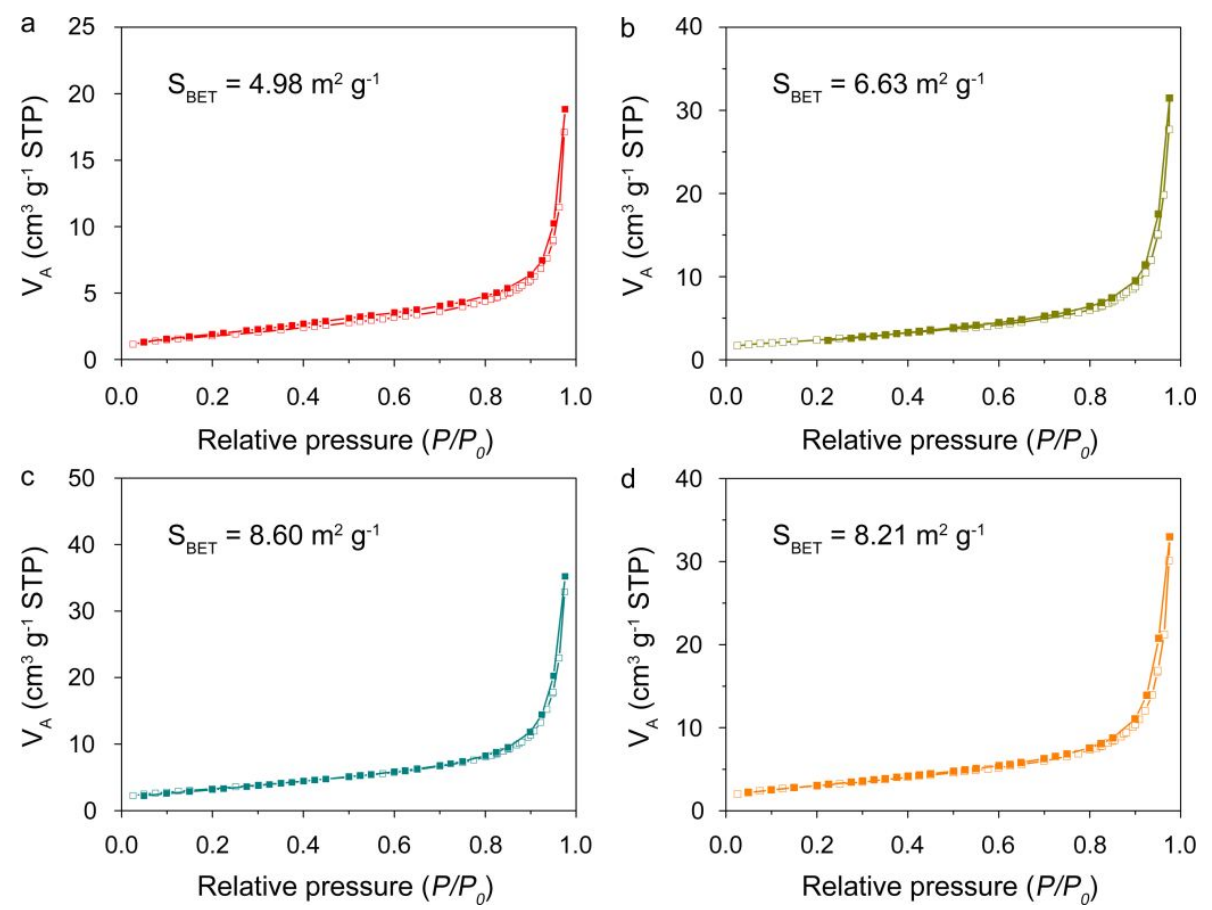

Figure S3. Nitrogen adsorption-desorption isotherm curves for (a) pristine $\mathrm{LiCoO}_{2}$, (b) $0.5 \%$ $\mathrm{La} / \mathrm{LiCoO}_{2}$, (c) $1 \% \mathrm{La} / \mathrm{LiCoO}_{2}$, and (d) $2 \% \mathrm{La} / \mathrm{LiCoO}_{2}$, respectively. 

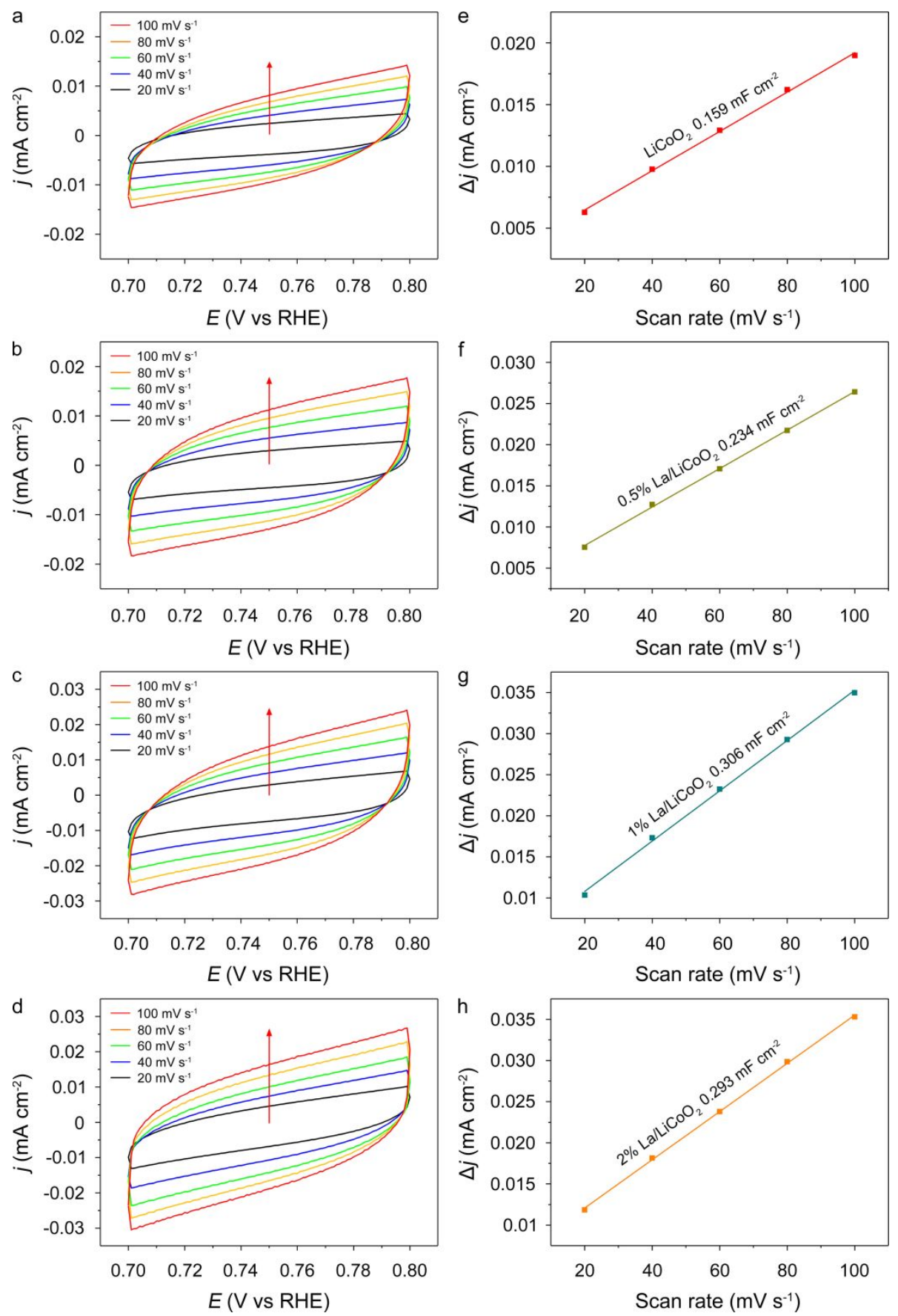

Figure S4. CV curves of (a) pristine $\mathrm{LiCoO}_{2}$, (b) $0.5 \% \mathrm{La} / \mathrm{LiCoO}_{2}$, (c) $1 \% \mathrm{La} / \mathrm{LiCoO}_{2}$, and (d) $2 \% \mathrm{La} / \mathrm{LiCoO}_{2}$ measured in $0.1 \mathrm{M} \mathrm{KOH}$ solution at different scan rates, respectively. Charging current density differences as a function of the scan rate for (e) pristine $\mathrm{LiCoO}_{2}$, (f) $0.5 \%$ $\mathrm{La} / \mathrm{LiCoO}_{2}$, (g) $1 \% \mathrm{La} / \mathrm{LiCoO}_{2}$, and (h) $2 \% \mathrm{La} / \mathrm{LiCoO}_{2}$, respectively. 


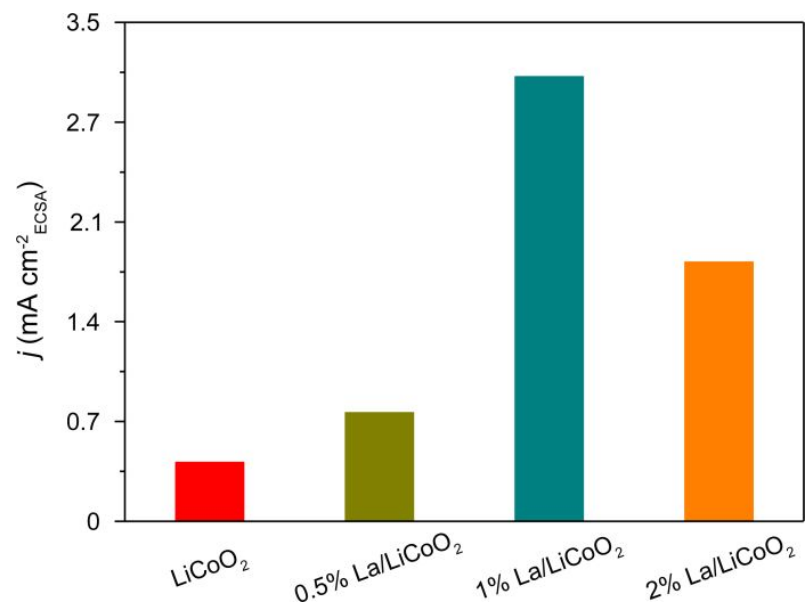

Figure S5. Specific activities calculated by normalizing current densities against electrochemically active surface areas (ECSA) at $\eta=0.35 \mathrm{~V}$. 


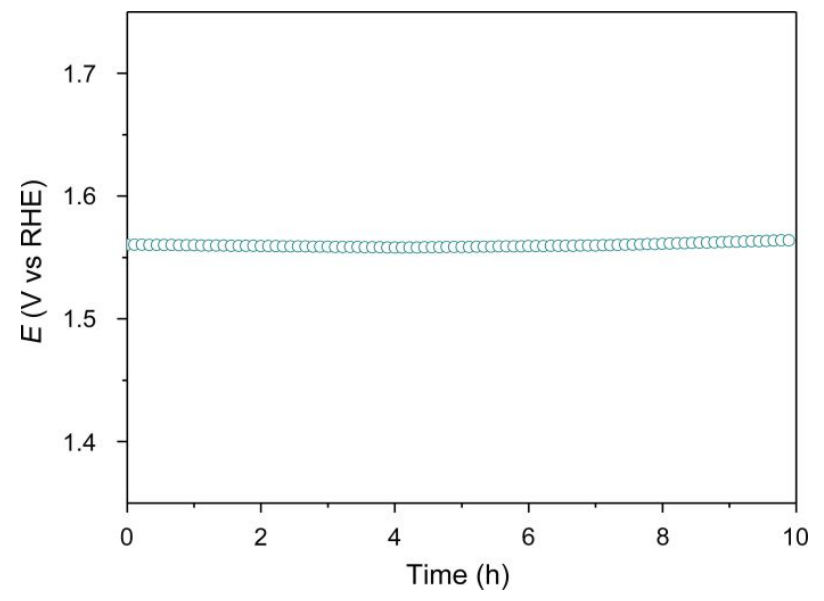

Figure S6. Chronopotentiometric measurement of $1 \% \mathrm{La} / \mathrm{LiCoO}_{2}$ at a current density of $10 \mathrm{~mA}$ $\mathrm{cm}^{-2}$. 

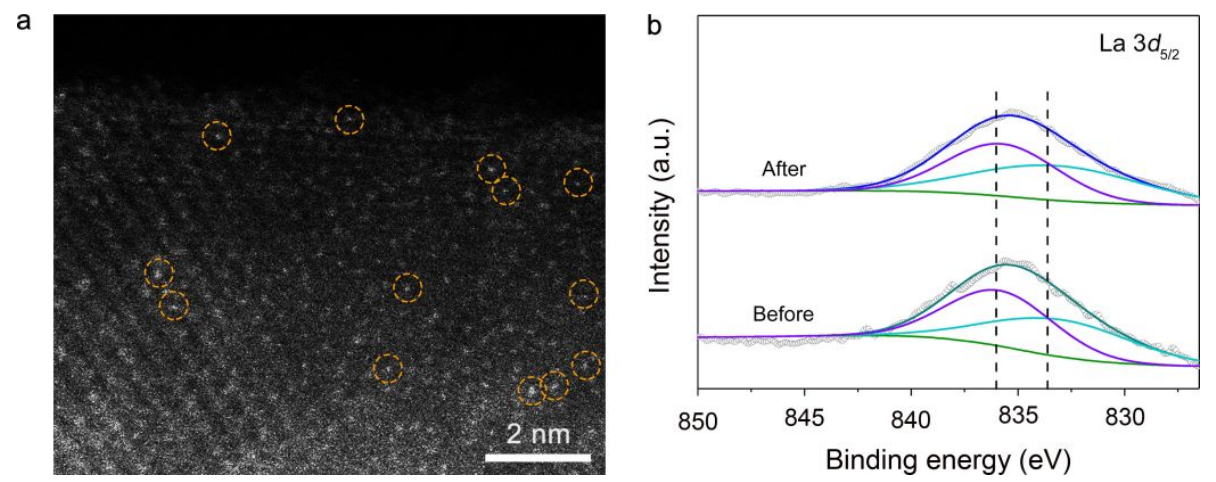

Figure S7. (a) $\mathrm{HAADF}$ image of $1 \% \mathrm{La} / \mathrm{LiCoO}_{2}$ after the durability test toward OER at $10 \mathrm{~mA}$ $\mathrm{cm}^{-2}$ for $10 \mathrm{~h}$. The individual La atoms are marked by yellow circles. (b) La $3 d$ XPS spectra of $1 \% \mathrm{La} / \mathrm{LiCoO}_{2}$ before and after the durability test. 

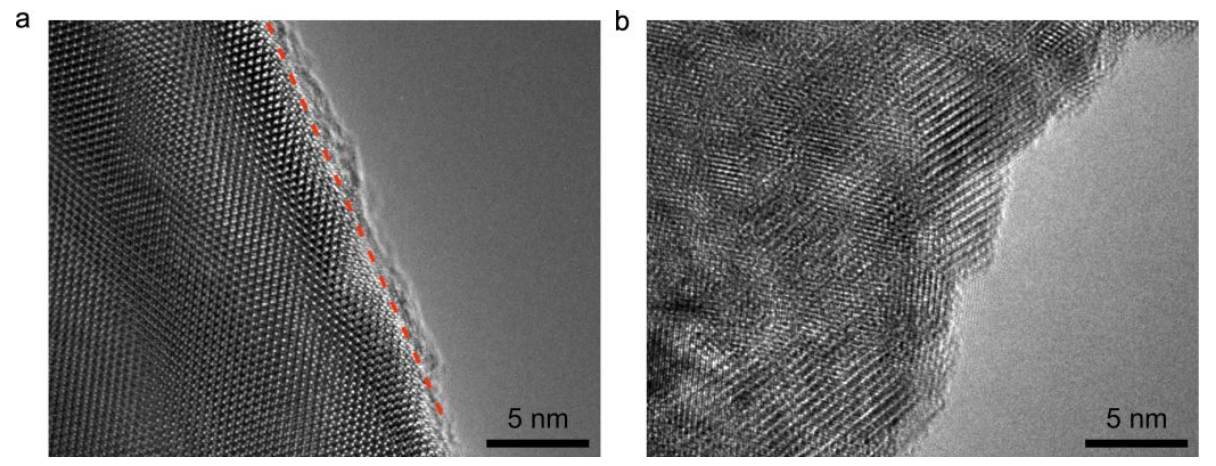

Figure S8. HRTEM images of (a) pristine $\mathrm{LiCoO}_{2}$ and (b) $1 \% \mathrm{La} / \mathrm{LiCoO}_{2}$ after the OER tests. The red dashed line showed the boundary between the ordered lattice fringes and amorphous phase. 


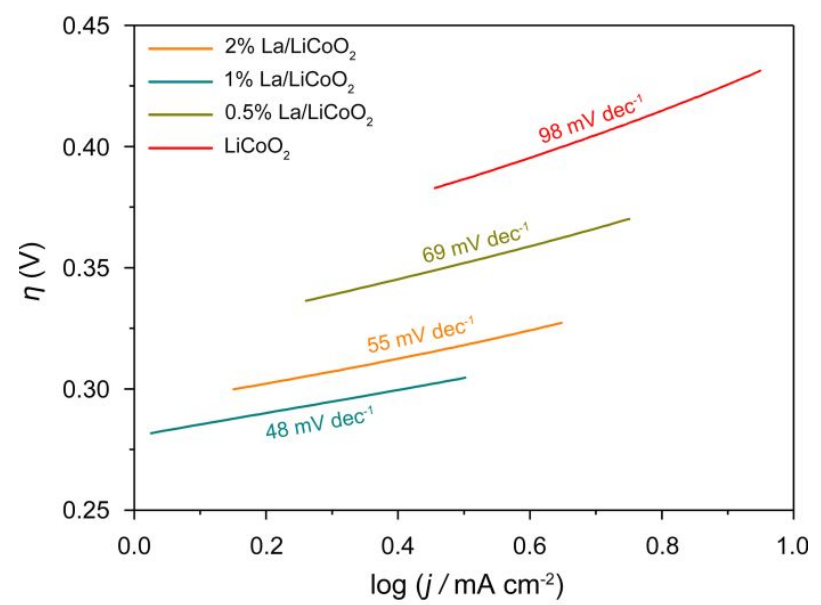

Figure S9. Tafel slopes of pristine $\mathrm{LiCoO}_{2}$ and $\mathrm{x} \% \mathrm{La} / \mathrm{LiCoO}_{2}(\mathrm{x}=0.5,1$, and 2). 


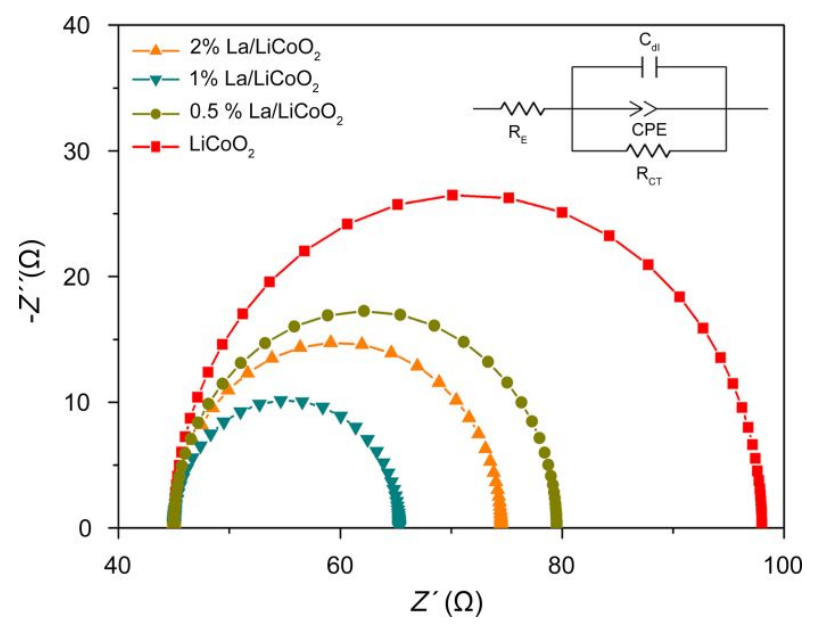

Figure S10. Electrochemical impedance spectra for pristine $\mathrm{LiCoO}_{2}$ and $\mathrm{x} \% \mathrm{La} / \mathrm{LiCoO}_{2}(\mathrm{x}=0.5$, 1 , and 2). 

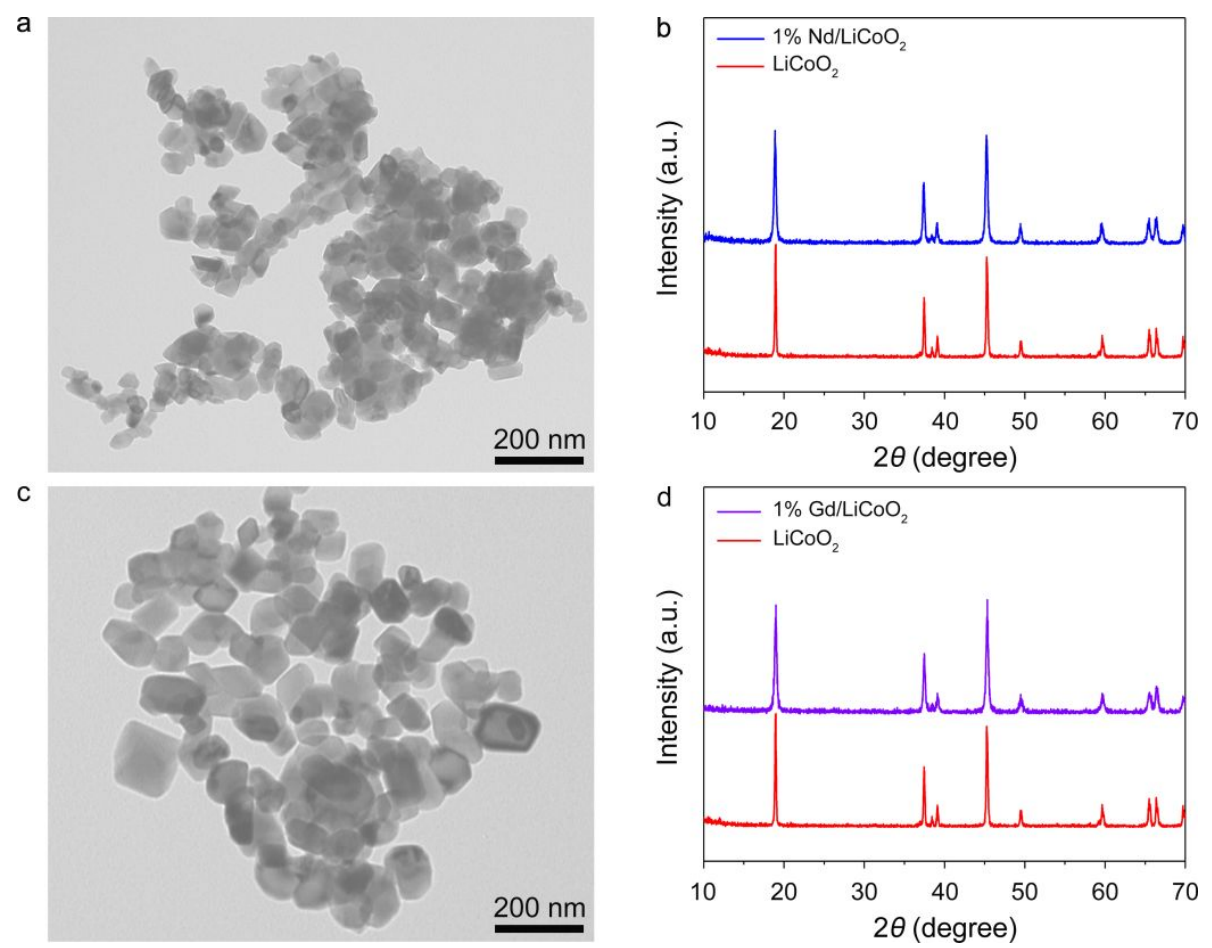

Figure S11. (a) TEM image and (b) XRD pattern of $1 \% \mathrm{Nd} / \mathrm{LiCoO}_{2}$. (c) TEM image and (d) XRD pattern of $1 \% \mathrm{Gd} / \mathrm{LiCoO}_{2}$. Pristine $\mathrm{LiCoO}_{2}$ was used as reference. 

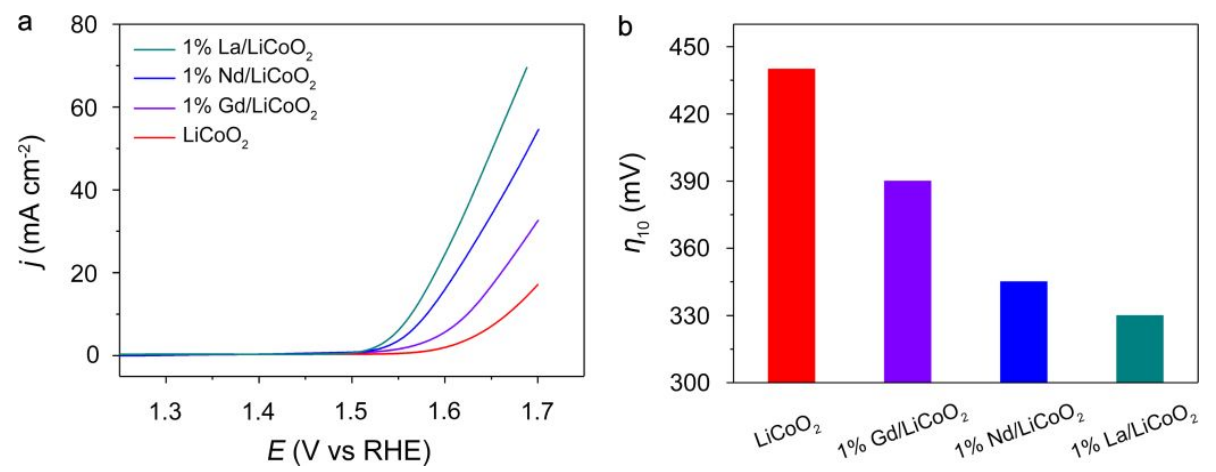

Figure S12. (a) Polarization curves of pristine $\mathrm{LiCoO}_{2}$ and $1 \% \mathrm{M} / \mathrm{LiCoO}_{2}$. (b) Overpotential of pristine $\mathrm{LiCoO}_{2}$ and $1 \% \mathrm{M} / \mathrm{LiCoO}_{2}$ at a current density of $10 \mathrm{~mA} \mathrm{~cm}{ }^{-2}\left(\eta_{10}\right) .(\mathrm{M}=\mathrm{Gd}, \mathrm{Nd}$, and La) 


\section{Reference}

(1) Kresse, G.; Furthmüller, J. Comput. Mater. Sci. 1996, 6, 15-50.

(2) Kresse, G.; Hafner, J. Phys. Rev. B 1993, 47, 558-561.

(3) Kresse, G.; Joubert, D. Phys. Rev. B 1999, 59, 1758-1775.

(4) Perdew, J. P.; Burke, K.; Ernzerhof, M. Phys. Rev. letters 1996, 77, 3865.

(5) Dudarev, S. L.; Botton, G. A.; Savrasov, S. Y.; Humphreys, C. J.; Sutton, A. P. Phys. Rev. B 1998, 57, 1505-1509.

(6) Ning, F.; Xu, B.; Shi, J.; Wu, M.; Hu, Y.; Ouyang, C. J. Phys. Chem. C 2016, 120, 18428-18434.

(7) Monkhorst, H. J.; Pack, J. D. Phys. Rev. B 1976, 13, 5188-5192.

(8) Maiyalagan, T.; Jarvis, K. A.; Therese, S.; Ferreira, P. J.; Manthiram, A. Nat. Commun. 2014, 5, 3949.

(9) Lu, Z.; Wang, H.; Kong, D.; Yan, K.; Hsu, P.-C.; Zheng, G.; Yao, H.; Liang, Z.; Sun, X.; Cui, Y. Nat. Commun. 2014, 5, 4345.

(10)Lu, Z.; Chen, G.; Li, Y.; Wang, H.; Xie, J.; Liao, L.; Liu, C.; Liu, Y.; Wu, T.; Li, Y.; Luntz, A. C.; Bajdich, M.; Cui, Y.J. Am. Chem. Soc. 2017, 139, 6270-6276.

(11)Zhu, Y.; Zhou, W.; Chen, Y.; Yu, J.; Liu, M.; Shao, Z. Adv. Mater. 2015, 27, 7150-7155.

(12)Niu, K.-Y.; Lin, F.; Jung, S.; Fang, L.; Nordlund, D.; McCrory, C. C. L.; Weng, T.-C.; Ercius, P.; Doeff, M. M.; Zheng, H. M. Nano Lett. 2015, 15, 2498-2503.

(13)Wang, J.; Li, L.; Tian, H.; Zhang, Y.; Che, X.; Li, G. ACS Appl. Mater. Interfaces 2017, 9 , 7100-7107. 